\title{
Dermatitis Paederus: About 06 cases occurred in Bunia, Democratic Republic of Congo
}

\section{Redouane Roukhsi $^{1^{*}}$, Monsef Elabdi ${ }^{2}$, Taher Nebhani ${ }^{3}$, Abdelilah Mouhcine ${ }^{1}$, Elmehdi Atmane $^{1}$, M'barek Mahfoudi', Abdelghani El Fikri'}

${ }^{1}$ Department of Radiology, Military hospital Avicenne, Marrakech, Morocco

${ }^{2}$ Department of orthopedics, HMIMV, Rabat, Morocco

${ }^{3}$ Emergency department, Military Training Hospital Med V, Rabat, Morocco

\section{Email address:}

redouan9990@hotmail.com(R. Roukhsi), elabdimonsef@gmail.com(M. Elabdi),nebhani@gmail.com(T. Nebhani), abdelilahmouhsine@yahoo.fr(A. Mouhsine), atmanemehdi@yahoo.fr(E. Atmane),mahfoudi@gmail.com(M. Mahfoudi), abdelghani@123.live.fr(A. Elfikri)

\section{To cite this article:}

Redouane Roukhsi, Monsef Elabdi, Taher Nebhani, Abdelilah Mouhcine, Elmehdi Atmane, M’barek Mahfoudi, Abdelghani El Fikri. Dermatitis Paederus: About 06 Cases Occurred in Bunia, Democratic Republic of Congo. American Journal of Life Sciences. Vol. 1, No. 4, 2013, pp. 171-173. doi: 10.11648/j.ajls.20130104.15

\begin{abstract}
The dermatitis Paederus is a dermatitis contact caused by caustic and vesicant activity of pederin. It occurs after skin contact with beetles Paederus kind belonging to the family Staphylinidae. The geographical distribution of these insects is global. Diagnosis is primarily based on clinical evidence and the epidemiological context. We report below six cases of pederose to Paederus occurred among the Moroccan Level II hospital staff in Bunia deployed in the framework UN peacekeeping operations in the Democratic Republic of Congo(MONUSCO).
\end{abstract}

Keywords: Dermatitis in Paederus, Paederus, Pédérine, Bunia

\section{Introduction}

Paederus dermatitis is a peculiar irritant contact dermatitis characterized by erythemato-bullous lesions of sudden onset on exposed areas of the body. The disease is caused by an insect belonging to genus Paederus [1]. (Fig. 1). These are known as agents of dermatitis, pédérose. Their hemolymph contains indeed a very complex amide named pederin[2], secreted by an inner Beetle Symbiotic Bacteria - closely looks like other species of Pseudomonas aeruginosa - that protects the insect against successive stages predatory spiders[3]. This substance is produced in the body of the female during oogenesis is transmitted to offspring in the egg (larva, pupa and imago male have that initial stock), while the symbiotic bacteria is also transmitted with the chorion.

In fact, I have, through the ensuing of six cases, shed light on the clinical appearance and evolution of this dermatitis [3].

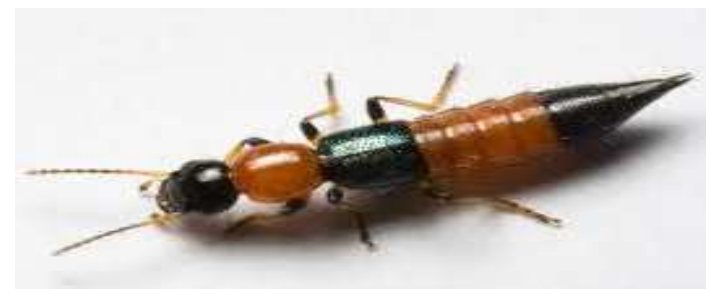

Fig.1: PAEDERUS RIPARIUS

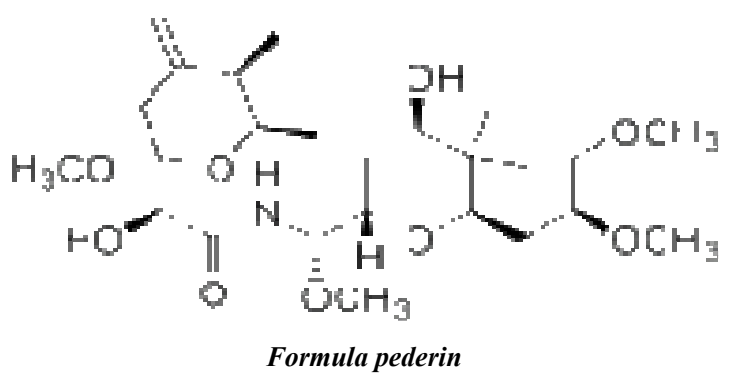

\section{Material and Methods}

The following study is conducted on six cases of pederose to Paederus occurred among Moroccan Level II 
hospital staff stationed in Bunia in the framework UN peacekeeping operations in the Democratic Republic of Congo.

Observation viewed on the 1st patient: (Fig. 2), 10 days after my arrival in the area, the below symptoms displayed in left side of neck are the origin of a pain with an itching sensation on the skin that evolved the next day into a very limited and regular erythematosus closet contours centered brownish papule that turns into the third day into an intense sensation of burns and erythema with excruciating headache.

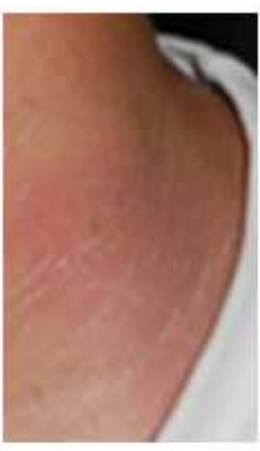

The $2^{\text {nd }}$ day

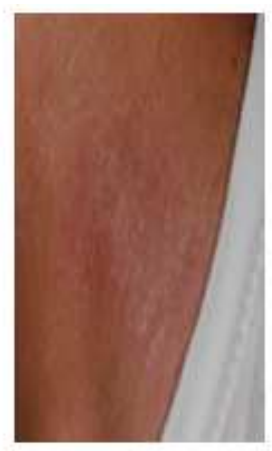

The $3^{\text {rd }}$ day

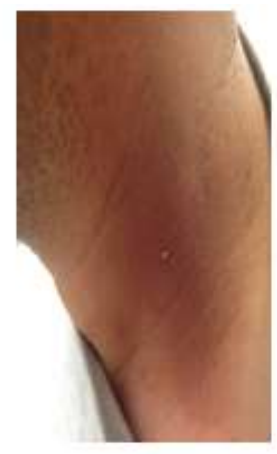

The $4^{\text {th }}$ day
Fig. 2: Evolution of the lesion for observation number1.

Observation got from the 2nd patient: (Fig. 3) double localization: nose and at the inguinal crease with increasing evolution of the burning sensation and erythema over four days.
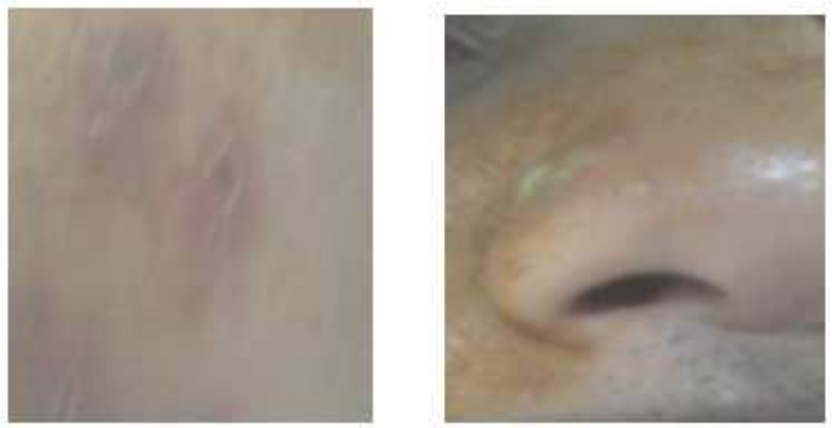

Fig. 3: double localization: nose and at the inguinal crease

Observation got from the 3rd patient: back double localization with burning sensation and erythematous with central ulceration in the two lesions. Observation got from the 4th patient: two lesions in the left forearm of the same appearance and evolution from the previous observation. Observation got from the 5th patient: facial lesion in the right cheek erythematous ulcerated, with a burning sensation that lasted a week, then gradual regression of the symptoms with remaining brownish stains. Observation got from the 06th patient: erythematous ulcerated lesion of the anterior chest wall with burning sensation completely regressed after fourth day of evolution.

\section{Results}

The face, hands, neck and forearms are the most commonly affected body parts (Table 1). Healing was noticed in $90 \%$ of cases after eight to ten days thanks to a dosing of a local treatment. Two patients received antibiotic therapy. The evolution of the lesion was longer in the cervical form (10 days) compared to other locations.

Table1.

\begin{tabular}{ccc}
\hline Affected Body Region & Number & \% \\
\hline Face & 2 & 33,3 \\
Neck & 1 & 16,6 \\
Torso & 1 & 16,6 \\
forearm & 1 & 16,6 \\
back & 1 & 16,6 \\
\hline
\end{tabular}

\section{Discussion}

The dermatitis Paederus or pederose is a contact dermatitis caused by a caustic and vesicant activity pederin, which is more toxic than cobra venom $[1,4,6]$. It occurs after a skin or mucosal contact with a so-called beetle Paederus belonging to the Staphylinidae family [5]. This small creepy-crawly does not release pederin as a defensive secretion, but casually exudes chemical whenever people try to remove the bug by unintentionally crushing it on the skin of the exposed parts of body that therefore turns into a blistering skin.

Three different kinds are categorized to belong to the same sub-tribe Paederina which may cause dermatitis Paederus namely: Paederus, Paederidus and Megalopaederus. The geographical distribution of these insects is global, with a variable distribution by continents [7]. Most often, the action of crushing the insect on the skin leaves linear trace on the area affected by the exuded pederin so that the lesion will often have a linear appearance, hence the name "linear dermatitis." [8] Diagnosis is primarily based on clinical evidence and on epidemiological follow-up. The morphology and location of the dermatitis vary from case to case and usually the lesion looks like the accidental dropping of a caustic or hot liquid on the derma. The contact pederinskin does not have an instant visible end-result on the skin. It takes however 12 to 36 hours [9] to view a skin rash appearing and turning after a while into blisters. Injuries, including crusting and scalding may occur two to three weeks. With respect to this case, five patients have evolved favorably in less than a week; whereas, the one case has required a 15 days permanent dosing for prompt healing.

In addition, phytophotodermatitis should be considered as a principle differential diagnosis. So, there are many similarities to Paederus dermatitis including linear asymmetric areas of erythema, possible blister formation, and dyspigmentation. 
The treatment initially involves removing the irritant by washing the area with soap and water. The blistered site should be treated with cool wet soaks, followed by a strong topical steroid. Our patients have been cured with corticosteroids applied locally with antihistamines, associated in two cases with antibiotic therapy. The authors assume that antibiotics are useful because of the possible contamination of the skin by bacteria producing pédérine $[7$, 9, 10].

Avoiding Paederus dermatitis constitutes the primary measure for preventing human-beetle contact. The recognition ability of Paederus beetles is proving to be an indispensable wariness, also avoiding crushing these insects will help decrease these eruptions. Besides, the removal of the beetle, once noticed lying on the skin, should be done through a smooth blowing off or by using a piece of paper to isolate its contact to skin. Immediately the area in contact with this insect should be washed with soap and water, and clothes as well. Doors should be kept closed and ascertain that windows screening are in a good state so as to minimize their entrance into buildings. Since lights obviously attract the beetles, so these should be kept switched off especially in bedrooms during sleeping time [11]. However, it seems inconvenient to resort to insecticides to control Paederus because the areas of their breeding are large and often difficult to pinpoint, which makes the process difficult to come off [12].

\section{Conclusion}

The above-mentioned preventive measures against predatory beetle are essential and must be taken inseparably as a cure based also on immediate washing of the skin in contact with the irritant.

\section{Acknowledgments}

I pay tribute to my dear friend Mokdim Yassin for his noteworthy contribution and support to translate some references from French into English and for his pertinent observations to make out this article.

\section{Conflict of interest}

None

\section{References}

[1] C.Malvy. D, Guevart, É. Laloge, V. Ezzedine. “ Dermatite à Paederus : étude rétrospective de 74 cas survenus en 2008 à Conakry, Guinée ". In Annales de Dermatologie et de Vénéréologie $2010 ; 137: 189-193$

[2] A. Fraval, “ De l'insecte dans les piqûres Insectes " $14 \mathrm{n}{ }^{\circ}$ $138-2005$ (3).

[3] M.R. Nikbakhtzadeh, " Medically important beetles (insecta: coleoptera) of Iran ". J. venom. anim. toxins incl. trop. dis., vol. 14 , no 4 , 2007, p. 597-618

[4] S.N. Rasool Qadir, "Paederus dermatitis In Sierra Leone". Dermatology online journal, vol: $12, \mathrm{~N}^{\circ}: 7,2006$.

[5] "Ectoparasites", Institute of Tropical Medicine, Antwerp. Retrieved on: 2007 - 06 - 04.

[6] V. Alva-Dávalos, V.A. Laguna-Torres, A. Huamán, R. Olivos, M. Chávez, C. García. "Epidemic dermatits by Paederus irritans in Piura, Perú at 1999, related to El Niño phenomenon". Rev. Soc. Bras. Med. Trop. vol.35 no.1 Uberaba Jan./Feb. 2002.

[7] G. Drouet, M. Glaizal, C. Schmitt, M. Kervégant, L. Tichadou, L. Haro, "Pédérose ou dermatite à Paederus : quatre observations en Provence". La Presse Médicale - Vol. 42 - $\mathrm{N}^{\circ} 3$ - p. 355-357.

[8] H. Coiffait "Coléoptères Staphylinidae de la région paléarctique occidentale. IV. Sous-famille Paederinae, tribu Paederini 1 (Paederi, Lathrobii) ". Nouv Rev Entomol, 1982, $12,440 \mathrm{pp}$.

[9] P. Couppié, F Beau, E Grosshans, “Ann "Paederus dermatitis : à propos d'une épidémie à Conakry (Guinée) en novembre 1989". Dermatol Vénéréol, 1992, 119, 191-195.

[10] J.H. Frank, K. Kanamitsu "Paederus, sensulato (Coleoptera: Staphylinidae): natural history and medical importance". J Med Entomol, 1987, 24, 155-191.

[11] J.J. Mammino, D.O. Faocd, "Paederus Dermatitis. An outbreak on a medical mission boat in the amazon" J Clin Aesthet Dermatol. 2011 November, 4 (11): 44-46.

[12] Frank JR, Kanamitsu K. Paederus, sensu lato (Coleoptera: Staphylinidae): natural history and medical importance. J Med Entomol. 1987;24: 155-191. 